\title{
Acúmulo de sementes de Acrocomia aculeata (Arecaceae) na bochecha de búfalos no Pará ${ }^{1}$
}

\author{
José Diomedes Barbosa ${ }^{2 *}$, João Maria do Amaral Junior ${ }^{2}$, Cleyton Prado \\ Pinheiro $^{2}$, Cairo Henrique Sousa Oliveira², Carlos Magno Chaves Oliveira², \\ Melina Garcia Saraiva de Sousa ${ }^{2}$ e Marcos Dutra Duarte ${ }^{2}$
}

\begin{abstract}
Barbosa J.D., Junior J.M.A., Pinheiro C.P., Oliveira C.H.S., Oliveira C.M.C., Sousa M.G.S. \& Duarte M.D. 2009. [Acumulation of the seeds of Acrocomia aculeata (Arecaceae) in the cheeks of buffaloes in the State of Pará, Brazil.] Acúmulo de sementes de Acrocomia aculeata (Arecaceae) na bochecha de búfalos no Pará. Pesquisa Veterinária Brasileira 29(5):431-434. Central de Diagnóstico Veterinário, Faculdade de Medicina Veterinária, Universidade Federal do Pará, Campus Castanhal, Rua Maximino Porpino da Silva 1000, Castanhal, PA 68740-080, Brazil. E-mail: diomedes@ufpa.br

A condition of buffaloes characterized by an increased volume of one of the cheeks was shown to be due to accumulation of the seeds of the palm-tree "mucaja" (Acrocomia aculeata) and of grass, in the oral vestibulum during rumination. This caused compressive atrophy with thinning and medial deviation of the corresponding submaxillary bone and exposition of the roots of molar teeth. The seeds appear to be of good palatability to the buffaloes.
\end{abstract}

INDEX TERMS: Acrocomia aculeata, Arecaceae, buffaloes.

RESUMO.- Foi demonstrado que uma condição em búfalos caracterizada pelo aumento de uma das bochechas é causada pelo acúmulo das sementes da palmeira "mucajá" (Acrocomia aculeata, fam. Arecaceae) e de capim no vestíbulo oral, durante a ruminação. Esse acúmulo de sementes causou atrofia por compressão com adelgaçamento e desvio medial do osso mandibular correspondente e exposição das raízes dos dentes molares. Aparentemente os frutos dessa palmeira possuem boa palatabilidade para búfalos.

TERMOS DE INDEXAÇÃO: Acrocomia aculeata, Arecaceae, "Búfalos Pelicanos", bufalos.

\section{INTRODUÇÃO}

No estado do Pará foram observados bubalinos com aumento de volume unilateral na região das bochechas, fato

\footnotetext{
${ }^{1}$ Recebido em 9 de janeiro de 2009.

Aceito para publicação em 22 de janeiro de 2009.

${ }^{2}$ Central de Diagnóstico Veterinário da Faculdade de Medicina Veterinária, Universidade Federal do Pará, Campus Castanhal, Rua Maximino Porpino da Silva 1000, Centro, Castanhal, PA 68740-080, Brasil. *Autor para correspondência: diomedes@ufpa.br
}

que tem chamado atenção, pelo impacto visual que causa. Os animais afetados foram batizados de "Búfalos Pelicanos". Segundo o histórico obtido na ocasião da visita, as alterações eram observadas há pelo menos um ano e meio e estavam associadas à ingestão dos frutos de uma palmeira comum na região, conhecida popularmente por mucajá. Este trabalho teve como objetivo caracterizar a doença e estudar sua etiopatogenia.

\section{MATERIAL E MÉTODOS}

O estudo consistiu na obtenção do histórico sobre a ocorrência da doença, no exame clínico dos animais afetados, com ênfase no exame da cavidade bucal, inclusive através da abertura cirúrgica da bochecha do lado comprometido de um búfalo e após a morte de um destes animais, no exame dos ossos da cabeça e na inspeção dos pastos, com coleta de material botânico para identificação da palmeira suspeita de estar envolvida na etiologia da doença.

\section{RESULTADOS}

A enfermidade foi observada em duas propriedades rurais, uma com 22 e a outra com 35 bubalinos, localizadas 


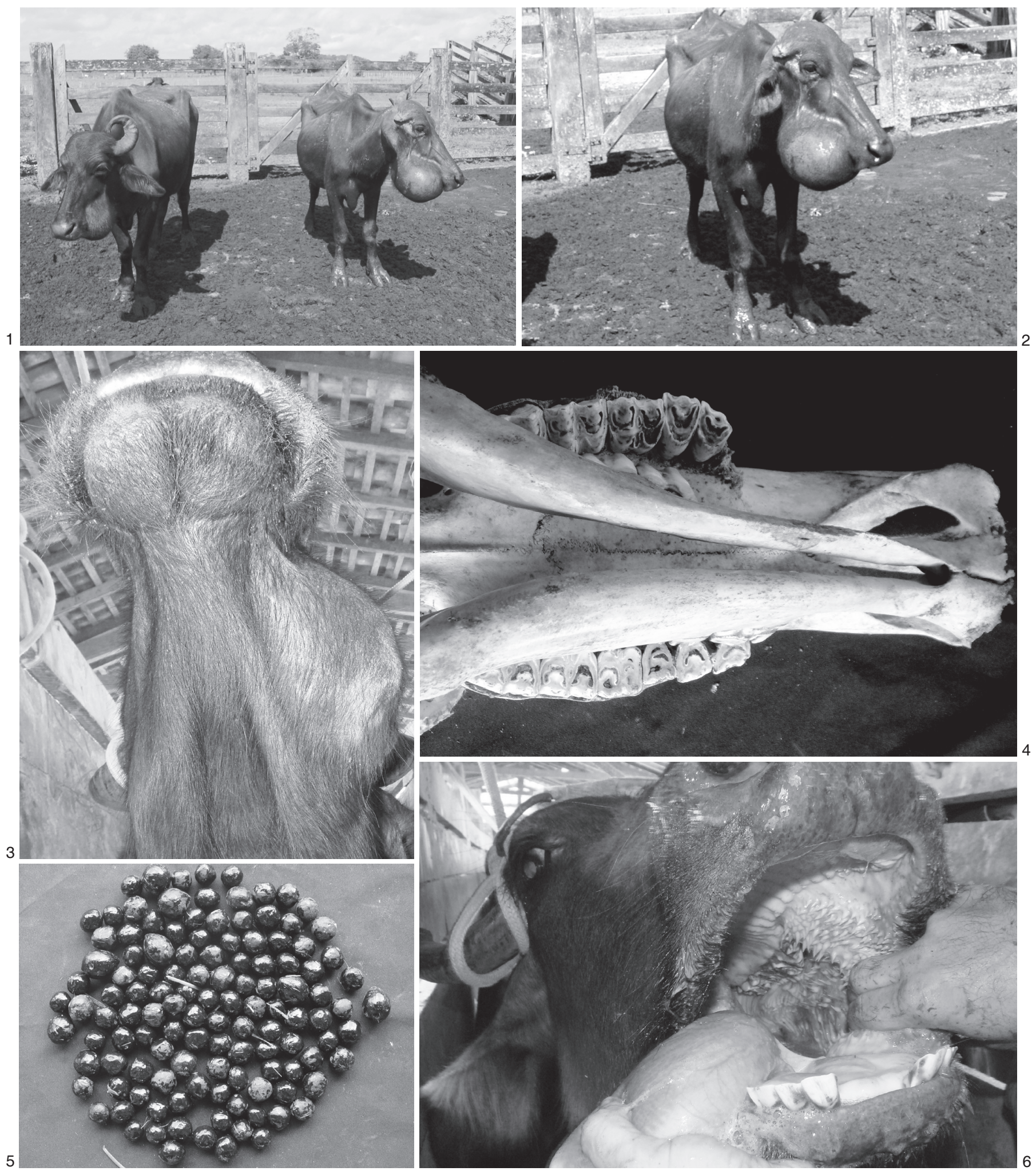

Fig.1. Búfalos com aumento de volume unilateral das bochechas.

Fig.3. Corpo da mandíbula adelgaçado devido ao acúmulo de sementes da palmeira "mucajá" e capim na bochecha.

Fig.5. Sementes da palmeira "mucajá" retiradas do vestíbulo oral do animal da Fig.2.
Fig.2. Detalhe do aumento de volume da bochecha do animal da direita da Fig.1.

Fig.4. Desvio unilateral do corpo da mandíbula devido à pressão do conteúdo acumulado na bochecha.

Fig.6. Vestíbulo oral depois de retirada das sementes de "mucajá" e do capim. 

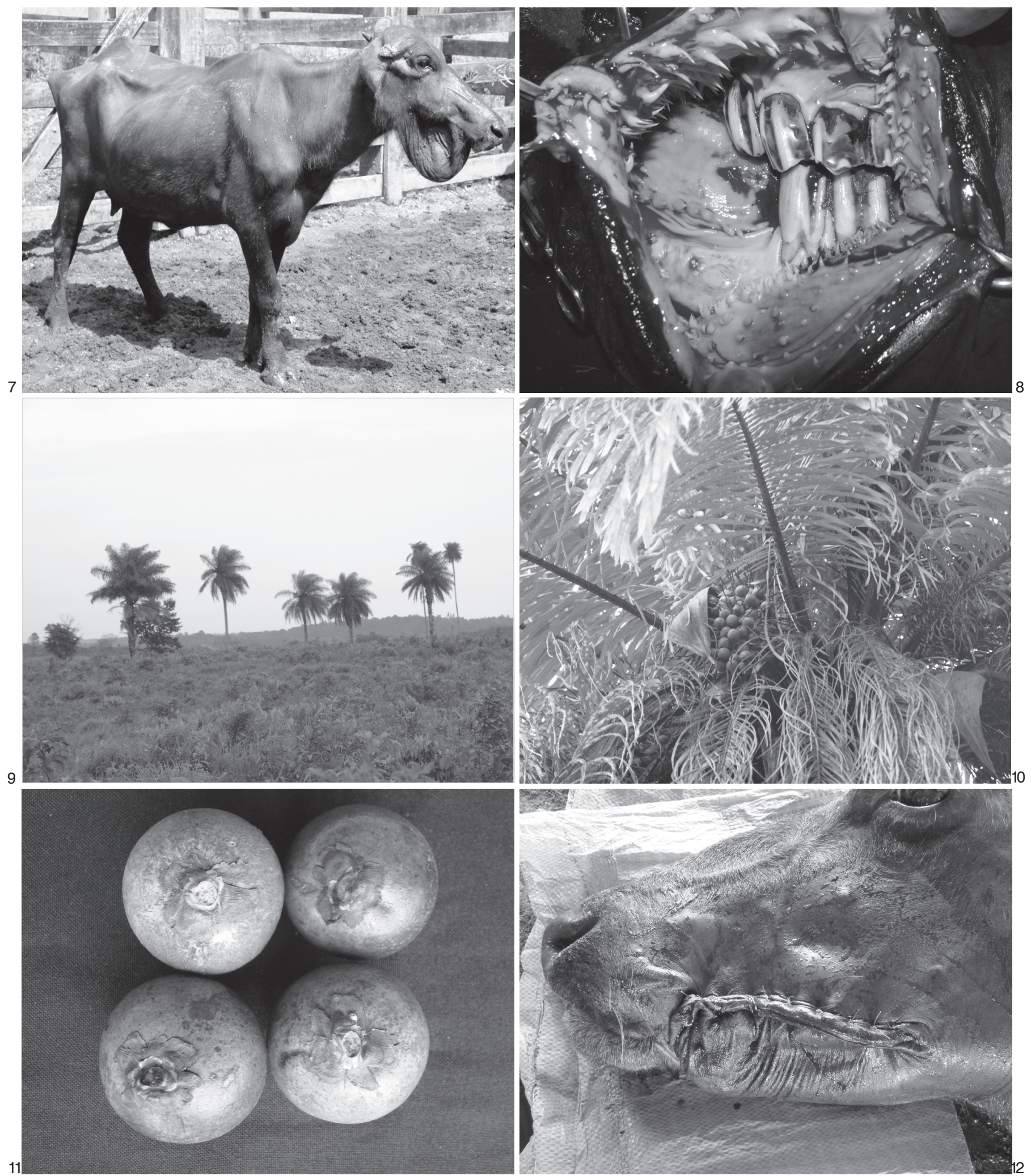

Fig.7. Bochecha vazia depois de retirada das sementes de "mucajá" e do capim, com aspecto de uma bolsa vazia.

Fig.9. Diversas palmeiras em pasto de Brachiaria brizantha no município de Ourém, PA.

Fig.11. Frutos maduros da palmeira "mucajá".

Fig.8. Retração gengival com exposição das raízes dos dentes molares inferiores.

Fig.10. Cacho de frutos da palmeira "mucajá".

Fig.12. Búfala após a retirada de parte da pele da bochecha. 
no município de Ourém, PA. Em cinco animais (dois em um estabelecimento e três em outro), fêmeas, da raça Murrah, com idades entre 4 e 10 anos, havia aumento de volume unilateral nas bochechas (Fig.1 e 2). Nessas propriedades o sistema de criação era extensivo, em pastagens de Brachiaria brizantha, com suplementação mineral insatisfatória. Esse aumento variou do tamanho correspondente a uma bola de tênis até ao de uma bola de basquete. O exame clínico dos animais acometidos revelou ainda, desvio lateral da mandíbula para o lado oposto ao do acúmulo de alimento. O corpo mandibular do lado afetado apresentava-se adelgaçado (Fig.3) e desviado medialmente (Fig.4), pela pressão do conteúdo acumulado no local. Em quatro dos animais afetados foi constatada fratura do processo cornual. Após a contenção dos animais e com o uso de um abre-boca, procedeu-se a retirada do conteúdo acumulado, que era constituído, basicamente, por sementes da palmeira "mucajá" (Fig.5) e por capim; em um animal havia também fragmento de osso. O peso do material acumulado variou de 0,2 (nos casos iniciais) a $5,6 \mathrm{~kg}$ (nos casos antigos). Após a retirada do conteúdo (Fig.6), a bochecha tomou o formato de uma bolsa vazia (Fig.7).

Em um animal realizou-se a abertura cirúrgica da bochecha com a finalidade de se retirar o excesso de pele e melhor avaliar a natureza das lesões na cavidade bucal. Verificou-se acentuada retração gengival com exposição das raízes dos dentes molares inferiores no local do acúmulo (Fig.8). Constatou-se um desgaste menor da parte externa dos dentes molares superiores devido à falta de atrito com os molares inferiores, causada pelo desvio lateral da mandíbula, provocado pelas sementes acumuladas.

Em um animal que veio a óbito em virtude da doença, foi possível uma observação mais detalhada das alterações clínicas descritas acima.

Foi realizada a inspeção da pastagem onde os animais se alimentavam e constatou-se a presença de numerosas palmeiras "mucajá", (Fig.9) que em determinada época do ano produzem uma grande quantidade de frutos (Fig.10) semelhantes a pequenos cocos (Fig.11). Esses, quando maduros, caem ao chão e são ingeridos pelos búfalos. Durante a ruminação, as sementes são eliminadas e caem ao chão, porém em alguns animais elas vão se acumulando no vestíbulo oral.
A palmeira foi identificada com Acrocomia aculeata. Ela possui ampla distribuição no Brasil e é conhecida popularmente por "mucajá", "macajá", "macaíba", "cocobabão", "coco-de-catarro" "macaúba", "coco-de-espinho" e "bocaiúva", e em determinadas regiões, como "chicletede-boi" (Aristone et al. 2006).

Segundo históricos, a mesma doença ocorre em búfalos no município de Soure, Ilha de Marajó, e em Nova Timboteua onde os búfalos são contidos periodicamente para retirada manual destes frutos. Provavelmente esses frutos apresentam boa palatabilidade, uma vez que os animais os ingerem em grandes quantidades, mesmo quando há boa oferta de pastagem.

\section{DISCUSSÃO}

Os estudos demonstram que a dilatação do vestíbulo oral foi causada pelo acúmulo progressivo das sementes de Acrocomia aculeata durante a ruminação e que o atrito constante das sementes duras desta palmeira, durante a ruminação, foram responsáveis pelas alterações dentárias e ósseas, uma vez que, alojadas no vestíbulo oral tornase difícil a sua saída espontânea. Porém, não podemos descartar a participação da deficiência de fósforo no agravamento das alterações ósseas, uma vez que, todos os animais portadores desta enfermidade apresentavam sinais desta deficiência como fraturas, osteofagia e baixa resistência óssea, evidenciados no animal que morreu.

O acúmulo de alimentos nas bochechas e o desvio lateral da mandíbula são também observados em animais com lesão dos nervos trigêmeo e facial (Riet-Correa et al. 1998), o que não foi constatado ao exame clínico nesses casos.

Desta maneira, uma forma de prevenir esta enfermidade seria uma suplementação mineral adequada à base fósforo e impedir o acesso dos animais às pastagens onde existe a palmeira, na época da queda dos frutos.

\section{REFERÊNCIAS}

Aristone F. \& Leme F.M. 2006. Como fazer farinha de Bocaiúva: Guia completo e livro de receitas (Manual didático). UFMS/CNPq, Campo Grande, MS.

Riet-Correa F., Riet-Correa G. \& Schild A.L. 2002. Importância do exame clínico para o diagnóstico das enfermidades do sistema nervoso em ruminantes e eqüídeos. Pesq. Vet. Bras. 22:161-168. 